\title{
Research Paper: Epidemiology of Shoulder and Elbow Injuries in Iranian Baseball Premier League
}

\author{
Mohammad Hossein Archin ${ }^{1}$ D, Mohammad Karimizadeh Ardakani ${ }^{* *}$, Fereshteh Hosseini ${ }^{2}$ (D) Fariba Kheirmahi $^{2}$ (D) \\ 1. Department of Health and Sport Medicine, Faculty of Physical Education and Sport Sciences, University of Tehran, Tehran, Iran \\ 2. Department of Health and Sport Medicine, Faculty of Physical Education and Sport Sciences, Ferdowsi University of Mashhad, Mashhad, Iran.
}

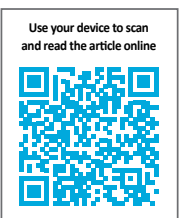

ditration Archin MH, Karimizadeh Ardakani M, Hosseini F, Kheirmahi F. Epidemiology of Shoulder and Elbow Injuries in Iranian Baseball Premier League. Physical Treatments. 2020; 10(2):107-116. http://dx.doi.org/10.32598/ptj.10.2.444.1

doi) $h$ http://dx.doi.org/10.32598/ptj.10.2.444.1

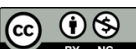

Article info:

Received: 18 Nov 2019

Accepted: 10 Mar 2020

Available Online: 01 Apr 2020

Keywords:

Epidemiology, Shoulder injuries, Injury report form, Baseball, Iran

\begin{abstract}
A B S T R A C T
Purpose: Baseball is a team sport that has a total of nine main players and includes explosive, endurance, and strength movements that can cause multiple injuries over a season due to repetitive movements, long training, and competition. The purpose of the present study was to investigate the epidemiology of shoulder and elbow injuries in Iranian Premier League baseball players.

Methods: 79 players participate in the Iranian Baseball Premier League, of whom 23 players had shoulder and elbow injuries with a mean age of $26.13 \pm 5.89$ years and an average experience of $7.93 \pm 5.99$ years playing baseball during three years. They were assessed during the three seasons of 2019 using a modified injury report form.

Results: The results showed the highest number of injuries among the various posts; the pitcher (43.5\%) and the players with 1-5 years of experience (47.8\%) showed more injuries than more experienced players (more than 5 years). Injuries in training were more than competitions $(60.86 \%)$. The shoulder injury was more during the training $(78.6 \%)$ and competition $(55.6 \%)$ than the elbow area. Strain, rupture, and muscle contusion were the most common types of injury among players with a prevalence of $52.2 \%$. The most common types of injuries were non-contact (78.3\%) and overuse (69.9\%). Fatigue was one of the most important causes of injury during training $(42.9 \%)$ and competitions $(55.6 \%)$.
\end{abstract}

Conclusion: According to the results, coaches can develop strategies to prevent and reduce injuries in this sport.

\section{* Corresponding Author:}

Mohammad Karimizadeh Ardakani, PhD.

Address: Department of Health and Sport Medicine, Faculty of Physical Education and Sport Sciences, University of Tehran, Tehran, Iran. Phone: +98 (910) 4963054

E-mail:m.karimizadeh@ut.ac.ir 


\section{Highlights}

- Less experienced players were exposed more shoulder and elbow injuries than experienced players.

- Pitcher players were found with more injuries than other players in training and competitions.

- The prevalence of injuries was generally greater during training than in competitions, and at both times, the shoulder was more injured than the elbow.

- Muscle injuries, including strains and contusion, account for about half of all injuries.

- The mechanism of most injuries is overuse and they are also often non-contact.

\section{Plain Language Summary}

Coaches and players use epidemiological information to become aware of the prevalence of injury in their sports and reduce it through exercise or preventive measures. In this study, we used an injury report form to determine the prevalence, type, mechanism, and causes of injury in Iranian baseball players during 2019 season. The results showed that players in the pitcher position who had the most throws during each competition and training suffered more injuries than other players. The overall prevalence of injuries during training was more than in competitions. At both times, the injury to the shoulder was more prevalent than the elbow. Muscle injuries, including strains and contusion, account for about half of all injuries. The mechanism of the most of injuries was overuse which was also often non-contact. Therefore, it is recommended that trainers develop exercises to strengthen the muscles and muscle chain involved; also, they should consider a proper recovery and rest period to prevent common injuries.

\section{Introduction}

aseball was inspired by an English game B that was common in the $19^{\text {th }}$ century in England. In 1845, Cartwright (father of baseball) formulated the rules of the game, and all teams were required to observe them and many of those rules are applied in today's baseball game, as well [1]. Currently, 86 countries have baseball federation and 19 countries are active in the Olympic field in Asia. Baseball was started in 1320 in Iran by the students of the Faculty of Physical Education and Sport Sciences. In 2007, the first season of the league was attended by four teams, but in the following year, the number of teams reached 12 .

Currently, there are 20 active sports associations in this field and the Iranian baseball league is being held in level 1 and level 2. Five teams compete against each other in Iran's League 1 (Premier), which is the most professional level in Iranian baseball competition. Baseball is a team sport with a total of 9 main players and includes explosive, endurance, and strength movements that can cause multiple injuries over a season due to repetitive movements, long training, and competition [2]. Playing in this sport, like all other sports, is associated with some dangers $[3,4]$. As baseball is one of the throwing sports, the upper extremity plays an important role; therefore, one of the most common injuries in baseball are shoulder and elbow injuries [5].

Due to the increasing number of athletes and baseball enthusiasts and the professionalization of the Iranian league, identifying risk factors in this field should be highly considered. Therefore, the coaches should identify the risk factors to prevent injuries in this field so that the players rejoin their teams with a minimum injury and faster. Thus, they can help themselves and their clubs. The first step in preventing sports injuries, according to the Van Michel model, is to identify the amount of incidence and prevalence of sports injuries [6]. It is also very important to determine the causes and the mechanism of injury as a second stage [6].

The role of epidemiology studies in answering these questions and in removing barriers to the use of the best preventive measures is so important. Although several studies on the epidemiology of baseball injuries have been conducted in other countries $[7,8]$, the role of cultural, geographical, and even race factors in the extent of the injury has not been established [9]. Epidemiological surveys also need to be updated every few years. Lack 
of awareness about the types and causes of injuries can increase the amount of injury and prolong the length of stay away from sports.

To the best of our knowledge, there was no study to investigate the epidemiology baseball injuries in Iran, and as mentioned it is important to implement epidemiological studies in different regions and cultures. Epidemiological studies can be a primer step in preventive tasks and put fewer burden on team members. Therefore, the purpose of this study was to identify and evaluate the risk factors and prevalence of shoulder and elbow injuries in the Iranian Premier League baseball players. Coaches and players can use the obtained results to organize their training and preparation to prevent common injuries. No relevant study has yet been done in Iran and this is the first study that can provide pieces of information for the coaches and the sports teams.

\section{Materials and Methods}

\section{Design}

This descriptive and prospective research was conducted on 21 Iranian baseball players out of 79 players (in five teams) playing in the premier league of Iran, with 23 injuries in shoulder and elbow during the three seasons of 2019 (Table 1). A modified injury report form in Persian specifically designed for this study was used to record the information related to injuries of the players. This form was approved by two sports scientists, two experienced baseball coaches, and the coach of the Iranian National baseball team. The injury report form included personal information, players' positions, playing experience, and type and mechanism of injury [10]. After the competition, the players were randomly asked to complete the form. The players spent about $10 \mathrm{~min}$ on this form and completed it with the companionship of the interviewer. All data gathered by the researcher who was a specialist in the field of sports injury and corrective exercise. The injury was defined as the injured player who was unable to continue the training session or competition due to physical contact or an athlete visited by a medical team to assess or treat his injury [11].

Descriptive statistics, frequency, and cross-tabulation were used to perform the statistical analysis in this study due to non-parametric data. Descriptive statistics, such as numbers, tables, and graphs were used to express the findings of the present study. All statistical analyses were performed using SPSS software V. 19.

\section{Results}

Players with 1-5 years of baseball experience more suffered from the shoulder and elbow injuries during the 2019 season (47.8\%). However, players with 6-10 years of experience had the least injuries $(21.7 \%)$ and players with more than 10 years of experience were between these two groups $(30.4 \%)$.

The highest rate of shoulder and elbow injuries among baseball players in the Iranian Premier League was recorded in pitchers $(43.5 \%)$. The second common injuries $(13 \%)$ were found in first base players (defender of first base). The most undefeated position among the Iranian Premier League players was the left field (Table 2). Generally, 23 different injuries were recorded in the Iranian League, 14 cases during training sessions $(60.86 \%)$ in position 1 , and 9 cases during the competition $(39.13 \%)$ in position 2 . There were 11 injuries $(78.6 \%)$ in the shoulder zone and only 3 injuries $(21.4 \%)$ in the elbow during the training session. Nine injuries were observed in the competitions, of which 5 cases $(55.6 \%)$ affected the shoulder, and 4 cases $(44.4 \%)$ affected the elbow.

Table 1. Demographic characteristics of the study participants

\begin{tabular}{|c|c|c|c|c|c|c|}
\hline \multirow{3}{*}{ Variables } & \multicolumn{6}{|c|}{ Players } \\
\hline & \multicolumn{3}{|c|}{ All } & \multicolumn{3}{|c|}{ Injured } \\
\hline & No. & Mean $\pm S D$ & Max-Min & No. & Mean \pm SD & Max-Min \\
\hline Age (y) & 79 & $26.69 \pm 5.74$ & $17-39$ & 21 & $26.13 \pm 5.89$ & $38-18$ \\
\hline Height (cm) & 79 & $179.75 \pm 7.6$ & 161-198 & 21 & $182.22 \pm 8.36$ & $198-161$ \\
\hline Weight (kg) & 79 & $76.31 \pm 13.19$ & $55-120$ & 21 & $82.26 \pm 17.46$ & $120-63$ \\
\hline Experience (y) & 79 & $7.91 \pm 5.56$ & $1-19$ & 21 & $7.93 \pm 5.99$ & $1-19$ \\
\hline
\end{tabular}


Table 2. Incidence of shoulder and elbow injury according to players' position

\begin{tabular}{|ccc|}
\hline Positions & No. (\%) & Position \\
\hline Pitcher & $10(43.5)$ & 1 \\
\hline Catcher & $2(8.7)$ & 4 \\
\hline First base & $3(13)$ & 2.5 \\
\hline Second base & $2(8.7)$ & 6.5 \\
\hline Third base & $1(4.3)$ & 6.5 \\
\hline Short stop & $1(4.3)$ & 6.5 \\
\hline Left field & $0(0)$ & 9 \\
\hline Center field & $1(4.3)$ & 6.5 \\
\hline Right field & $3(13)$ & 2.5 \\
\hline Total & $23(100)$ & \\
\hline
\end{tabular}

Table 3. Type of shoulder and elbow injury in training sessions and competitions of the Iranian Baseball League 1

\begin{tabular}{ccc}
\hline Variables & No. (\%) & Position \\
\hline Dislocation/semi dislocation & $2(8.7)$ & 3.5 \\
\hline Sprain/ligament injuries & $1(4.3)$ & 5 \\
\hline Strain/Rupture/Muscle contusion & $12(52.2)$ & 1 \\
\hline Tendon rupture and injuries/tendinosis/bursitis & $6(26.1)$ & 2 \\
\hline Bruises & $2(8.7)$ & 3.5 \\
\hline Total & $23(100)$ & - \\
\hline
\end{tabular}

The common types of shoulder and elbows injuries [11] during the Iranian Premier League were muscle strain, rupture, and contusion (52.2\%). The second common types of injury in this area were tendon rupture, tendinosis, and bursitis (26.1\%). Bruises, dislocations, and semi-dislocations also were observed in $8.7 \%$ of the players and the least common types of injuries were ligament and sprain injuries in shoulder and elbow (4.3\%) (Table 3). Also, $60.9 \%$ of the injuries were repetitive, and players experienced an injury at least once in the same area, and $39.1 \%$ of the injuries had occurred for the first time (Table 4). Approximately two-thirds of the shoulder and elbows injuries were overuse (69.9\%) in position 1 (16 out of 23), while one-third of the injuries were acute $(30.4 \%)$ in position 2 ( 7 out of 23 ).

Non-contact injury was the most important mechanism of injury during training sessions and competition (78.3\%), followed by falling, and contacts $(8.7 \%)$. Indirect contact was the least common mechanism of in- jury among professional baseball players in the Iranian league. Throwing with 9 cases was the main mechanism and cause of shoulder and elbow injuries during training sessions among Iranian baseball players (64.3\%), whereas catching with $14.3 \%$ (2 cases) and pitching, running, and base running with $7.1 \%$ ( 1 case) were other common mechanisms of injuries.

During the competition, pitching with $55.6 \%$ ( 5 cases) of the injuries was the most common mechanism of shoulder and elbow injury among players. Pitching (22.2\% (2 cases)) and hit by pitch and contact with other players (11.1\% (1 case)) were the next common injury mechanisms.

During the training sessions, the second baseman, pitcher, and outfield players suffered more from shoulder and elbow injuries $(21.4 \%)$. Also, players in the shortstop position were the second most affected cases by shoulder and elbow injuries (14.3\%), whereas first base players did not experience an injury (Table 5). 
Table 4. Level of reinjury in the same area in the Iranian league 1 baseball players

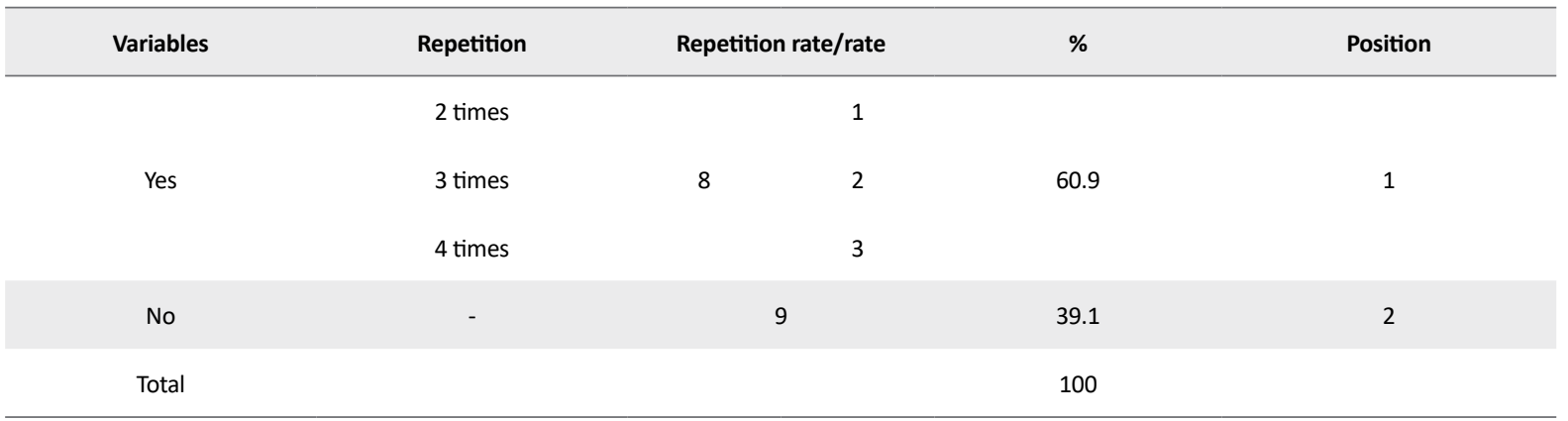

PHYSICAL TREA $\ M E N T S$

Table 5. Position of the players during training

\begin{tabular}{|ccc|}
\hline Position & No. (\%) & Position \\
\hline First base & $0(0)$ & 7 \\
\hline Second base & $3(21.4)$ & 2 \\
\hline Third base & $1(7.1)$ & 6 \\
\hline Short stop & $2(14.3)$ & 4 \\
\hline Catcher & $1(7.1)$ & 6 \\
\hline Pitcher & $3(21.4)$ & 2 \\
\hline Out field & $3(21.4)$ & 2 \\
\hline Runner & $1(7.1)$ & 6 \\
\hline Total & $14(100)$ & \\
\hline
\end{tabular}

PHYSICAL TREA $\pitchfork$ MENTS

Table 6. Position of players during competitions

\begin{tabular}{ccc}
\hline Positions & No. (\%) & Position \\
\hline First base & $1(11.1)$ & 3.5 \\
\hline Batter & $2(22.2)$ & 2 \\
\hline Catcher & $1(11.1)$ & 3.5 \\
\hline Pitcher & $5(55.6)$ & 1 \\
\hline Total & $9(100)$ & \\
\hline
\end{tabular}

PHYSICAL TREA $\ M E N T S$

During competitions, 5 out of 9 shoulder and elbow injuries were experienced by players in the pitcher position $(55.6 \%)$, while players in the batter position were observed with 2 injuries (22.2\%) and players in first base and catcher were found with one injury (11.1\%) (Table 6). In $73.9 \%$ of the cases ( 21 cases), the shoulder and elbow injuries were not due to falls or contact. Contact with other players, contact with the ball, and contacts with something else consisted of $8.7 \%$ of the other causes of injury in the area ( 2 cases). Also, 13 Injuries in the shoulder and elbow did not keep players away from work or education. However, 3 injuries caused 1-3 days off, 4 injuries caused 4-7 days away, 2 injuries caused 8-14 days away, and 1 injury caused more than 14 days away from work or education. Besides, 13 out of 23 injuries in elbow and shoulder did not keep players away from competition, while 6 injuries caused 1-3 days away from the competition (Figure 1).

The most important cause of shoulder and elbow injury during exercise was fatigue (42.9\%). Athletes' physical fitness and technique were also the second leading 


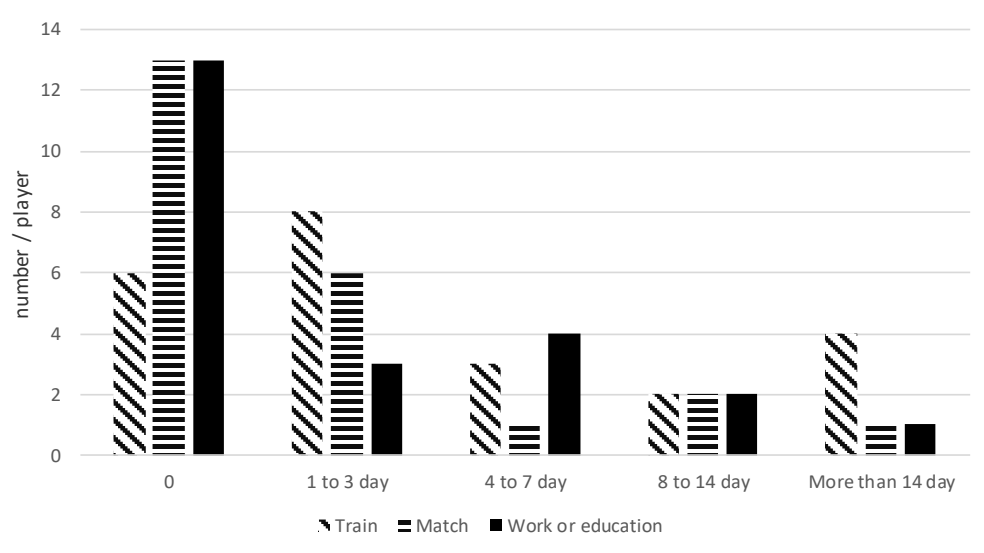

Figure 1. Players staying away from work or education due to shoulder and elbow injuries

cause of injury during training $(21.4 \%)$. The previous injury was another cause of shoulder and elbow injuries during training $(14.2 \%)$. Also, the main cause of shoulder and elbow injuries in the competitions was fatigue $(55.6 \%)$. Physical fitness, contact with the ball, athlete's technique, and opponent's technique were other causes of injury in the competition (1.11\%). Among all of the injuries in players during training and competitions, 13 cases were self-treatment $(56.5 \%)$. Medical treatment included 6 cases $(26.1 \%)$ and physiotherapy included 3 cases $(13 \%)$ of injury treatment.

\section{Discussion}

According to the results, players with 1 to 5 years of baseball experience had the highest number of injuries in the shoulder and elbow during a season (47.8\%). Age, height, playing for different teams, throwing (pitch), speed, and fatigue are risk factor of injuries in adults. The number of pitches per game is also considered as a risk factor of shoulder injury [12]. It seems that the less experienced or beginner players are at greater risk of injury than the more experienced players due to the incompatibility with this sport, in which the upper extremity is more used, as well as the lack of physical fitness. Also, beginner players in Iran are more likely for injures of the upper extremities, especially the shoulder and elbows, due to incorrect throwing pattern.

Based on the results, it can be concluded that players with 6-10 years of experience in baseball are likely to have the highest level of physical adaptation, as well as high physical fitness, which reduces the risk of injury. Also, players with more than 10 years of experience had a higher risk of injury due to prolonged use of the upper extremities and lack of physical fitness.
It has been reported that the most common shoulder injury mechanism is non-contact, including muscle tension (42\%) and overuse (35\%) [13]. The highest rate of shoulder and elbow injuries among baseball players in Iranian Premier League was recorded in pitchers (43.5\%). In total, injuries in the Professional League from 2011 to 2016 accounted for $39.1 \%$ of all injuries to pitchers [14]. pitchers experienced 34\% more damages than fielders [14]. The pitchers experienced a significant proportion of upper limb injuries compared with other players, while the fielders experienced significantly lower limb injuries than the players, with an average 56.6 days on the disabled list [14].

The pitchers experienced more days away from playing than other players [14]. The number of pitches per game is also considered as a risk factor of shoulder injury [12]. Like most of the professional leagues in the world, pitchers were more observed with injuries in the upper limbs compared with other positions. The number of pitches and fatigue has a direct relationship with injury in pitcher players. As Brandon et al, reported, the number of pitches increased with increasing pain and fatigue [15]. Generally, 23 injuries were recorded in the league, 14 cases during training sessions and 9 cases during competitions.

Previous studies have reported that most baseball shoulder injuries occur in training (65\%) [13]. The higher prevalence of injuries during training indicates that players are more likely for an increase in pressure on the upper limbs to raise their levels of readiness to succeed in competitions, which increases their risk of injury. Since baseball in Iran is not fallowed academically, lack of knowledge about training and also the lack of proper exercise planning can lead to more number of injuries during training sessions in shoulder and elbow. 
Out of 14 injuries occurred during training 11 injuries were in shoulder, and 3 were in elbow. At the time of the competition, there were 9 injuries: 5 shoulder injuries and 4 elbow injuries. Interestingly, in all American baseball professional league players with a forearm injury, the subsequent injury included $37 \%$ in the shoulder, $35.8 \%$ in the elbow, and $17.9 \%$ in the forearm [16]. Among all injuries affecting players, upper extremity injury accounted for $51.4 \%$, while lower extremity injury accounted for $30.6 \%$ of injuries. Spine and core muscle injuries accounted for $11.7 \%$, whereas other injuries and diseases accounted for $6.3 \%$ of total disabled list entries [6].

The greater frequency of shoulder injury during training and competition indicates that the upper extremity junction is more at risk of injury and requires more attention in prevention exercises. Among 23 injuries affecting the shoulder and elbows during the Iranian Premier League, the most common types of injuries were strain, rupture, and muscle contusion (52.2\%). Hamstring strain has been the most common injury among professional baseball players, followed by the rotator cuff strain and its tear [17]. Shoulder surgery is not common among professional players, and those who need surgery are often pitchers and it has been the biggest problem in the labrum [5].

Due to the structure of the upper limbs, as well as the type of function and mechanics of baseball throwing, strains and muscular injuries are the most common injuries. Rotator cuffs strain and tears, as well as problems with labrum that result from strain in the muscles, are the most common injuries to the shoulder and upper limbs. Tendon ruptures and inflammation are also the most common types of injuries due to repeated overhead throws during training and competitions. Also, $60.9 \%$ of injuries were repetitive and players experienced injuries at least once in the same area, and $39.1 \%$ of injuries occurred for the first time.

Due to the use of the same movement pattern in throwing and its repetition, reinjury is not unexpected among players. It has also shown that previous injuries in other areas of the upper extremity can potentially increase the risk of injury to adjacent limbs; thus, the extent of subsequent injury in players who had a forearm injury was much more significant than players without prior injury in the professional league [16]. Interestingly, in all American baseball professional league players with a forearm injury, the subsequent injury accounted for $37 \%$ of the shoulder, $35.8 \%$ of the elbow, and $17.9 \%$ of the forearm injuries [16]. Approximately, two-thirds of the shoulder and elbow injuries were overuse (69.9\%), whereas one-third of them were the acute injuries
$(30.4 \%)$. The modality of tendon and muscle injuries in the upper extremity are often repetitive and strain during fatigue, with results showing that approximately $70 \%$ of the injuries in this area were overuse.

It has also been reported that fatigue impedes the performance of movement sensors due to the inability of proper mechanics in repetitive movements [18]. Most of the other $30 \%$ have been due to the impact of hit by a pitch as it has shown that most of the areas affected by hits and pitches are hands and fingers, followed by head and face [19]. Throwing with $64.3 \%$ was the main mechanism and cause of shoulder and elbow injury during training sessions among Iranian baseball players. At the time of the competition, pitching with $55.6 \%$ of injuries was the most common mechanism of shoulder and elbow injury among players because of changes in coordination and the development of fatigue-related abnormal movement strategies that is related to the number of pitches resulting in pitcher exposure to further injury [18].

Throwing, catching, and pitching were the most common injury mechanism during training and competitions and are a non-contact modality. The trend of injury occurring in these functions often is to repeat these patterns repeatedly, even in fatigue, so that failure to recognize the position of the joint due to fatigue can increase the mechanical pressure of the joints and lead them to vulnerable positions [20]. During training, players in different positions were not immune to shoulder injury and there was no significant difference between the different positions, as the statistics of the Iranian League show in the position of second base, pitcher and out fields suffered the most number of shoulder and elbow injuries (21.4\%).

In general, positions and situations are at greater risk of shoulder and elbow injuries that have a higher and more important throwing task than others. The pitcher and catcher of each team are called the heart of team. The criterion for assessing a pitcher is the accuracy and power of his throw, while maintaining this performance for a long time and multiple times during a game, which repeated pitching causes fatigue and increases risk of injury to the upper extremity. Fatigue of shoulder muscles alters the kinematics of the glenohumeral and scapulothoracic joint and may lead to shoulder injury [21].

More than $50 \%$ of injuries (13 injuries) in the area have not caused players to drop out of education or work. It is also less common for players to lose their matches due to shoulder and elbow injuries, while players generally rest for more than one day during training sessions. The importance of competitions, education, and work for 
players than training has caused them to participate even though they are injured. However, during training, they have at least one day off to return to training.

The severity of injuries can also affect players and makes them stay away from training, competition, work, or education. Depending on how long the players have been away, it can be said that injuries that occurred in most cases with minor severity or remedies, made them less far from the playing. The most important cause of elbow and shoulder injuries during training is fatigue (42.9\%) because fatigue disrupts joint feedback to the central nervous system, which may lead to joint instability [18]. Athletes' physical fitness and technique were also the second leading cause of injury during training (21.4\%), followed by previous injury (14.2\%). Also, during competitions, fatigue was the main cause of shoulder and elbow injury $(55.6 \%)$. In general, a combination of reduced muscle strength and altered mechanics due to fatigue may put the athlete at greater risk for pain and injury [4].

\section{Conclusion}

In all cases, it can be concluded that players with high repetitions of pitching to reach fatigue and continuing exercise during fatigue are at a higher risk of injury, and the results of studies have indicated that the risk of injury at the end of training, competition, or a season has been increased because fatigued muscles are more vulnerable $[22,23]$. It is clear that players with high throwing positions and maintaining training pressure during fatigue are the most susceptible cases to injury to the shoulder and elbow, especially the risk of injuries that are often muscular and strain. Lower level of general physical fitness and specific physical fitness for baseball players are also risk factors for injury. Technical errors in throwing sports, such as baseball, and repeated high-intensity repetition, can cause injuries sometimes leading to surgery or special medical treatment.

This study had some limitations. For example, only male baseball players were studied, which may limit the generalizability of the results to females athletes. Other limitations were lack of access to psychological information and short duration of the research. Future studies should examine and compare injury incidence rates in both training and competition modes, as well as a comparison with the women's leagues to determine whether gender is an influential factor in baseball injury. It is also suggested to examine the impact of preventive interventions on the mechanisms and causes of injuries in the league.

\section{Ethical Considerations}

\section{Compliance with ethical guidelines}

All ethical principles were considered in this article.

\section{Funding}

This research did not receive any specific grant from funding agencies in the public, commercial, or nonprofit sectors.

\section{Authors' contributions}

All authors were equally contributed in preparing this article.

\section{Conflict of interest}

The authors declared no conflict of interest.

\section{Acknowledgments}

The authors would like to thank all player and team members that participated in this study.

\section{Reference}

[1] Seymour H. Baseball: The early years. Oxford: Oxford University Press; 1960. https:/ / books.google.com/books?id=17SAAAAMAAJ\&source

[2] Szymanski S, Zimbalist AS. National pastime: How Americans play baseball and the rest of the world plays soccer. Washington, D.C.: Brookings Institution Press; 2006. https:/ /books.google.com/books?id=c0vzRdntD0MC\&dq

[3] Chalmers DJ. Injury prevention in sport: Not yet part of the game? Injury Prevention. 2002; 8 Suppl 4(Suppl 4):IV22-5. [DOI:10.1136/ip.8.suppl_4.iv22] [PMID] [PMCID]

[4] Olsen SJ, Fleisig GS, Dun S, Loftice J, Andrews JR. Risk factors for shoulder and elbow injuries in adolescent baseball pitchers. The American Journal of Sports Medicine. 2006 34(6):905-12. [DOI:10.1177/0363546505284188] [PMID]

[5] Saper MG, Pierpoint LA, Liu W, Comstock RD, Polousky JD, Andrews JR. Epidemiology of shoulder and elbow injuries among United States high school baseball players: School years 2005-2006 through 2014-2015 American Journal of Sports Medicine. 2018; 46(1):37-43. [DOI:10.1177/0363546517734172] [PMID]

[6] van Mechelen W, Hlobil H, Kemper HC. Incidence, severity, aetiology and prevention of sports injuries. Sports Medicine. 1992; 14(2):82-99. [DOI:10.2165/00007256-199214020-00002] [PMID]

[7] Posner M, Cameron KL, Wolf JM, Belmont Jr PJ, Owens BD. Epidemiology of major league baseball injuries. 
American Journal of Sports Medicine. 2011; 39(8):1676-80. [DOI:10.1177/0363546511411700] [PMID]

[8] Kanematsu Y, Matsuura T, Kashiwaguchi S, Iwase T, Suzue N, Iwame T, et al. Epidemiology of shoulder injuries in young baseball players and grading of radiologic findings of Little Leaguer's shoulder. The Journal of Medical Investigation. 2015; 62(3-4):123-5. [DOI:10.2152/jmi.62.123] [PMID]

[9] Wiese-Bjornstal DM, Smith AM, Shaffer SM, Morrey MA. An integrated model of response to sport injury: Psychological and sociological dynamics. Journal of Applied Sport Psychology. 1998; 10(1):46-69. [DOI:10.1080/10413209808406377]

[10] Meir R, Weatherby R. Long-term injury consequences of playing baseball (a report to the New South Wales Sporting Injuries Committee) [Internet]. 2005 [Updated September 2005] Available from: https:/ / bit.ly/2WX4TOD

[11] Baker SP. The injury fact book. Oxford: Oxford University Press; 1992 . https://books.google.com/ books?id=nHcsMQAACAAJ\&dq

[12] Norton R, Honstad C, Joshi R, Silvis M, Chinchilli V, Dhawan A. Risk factors for elbow and shoulder injuries in adolescent baseball players: A systematic review. The American Journal of Sports Medicine. 2019; 47(4):982-90. [DOI:10.1177/0363546518760573] [PMID]

[13] Krajnik S, Fogarty KJ, Yard EE, Comstock RD. Shoulder injuries in US high school baseball and softball athletes, 2005-2008. Pediatrics. 2010; 125(3):497-501. [DOI:10.1542/ peds.2009-0961] [PMID]

[14] Rudi M, Robert W. Long-term injury consequences of playing baseball A report to the New South Wales Sporting Injuries Committee: Southern Cross University; 2005.

[15] Erickson BJ, Sgori T, Chalmers PN, Vignona P, Lesniak M, Bush-Joseph CA, et al. The impact of fatigue on baseball pitching mechanics in adolescent male pitchers. Arthroscopy. 2016; 32(5):762-71. [DOI:10.1016/j.arthro.2015.11.051] [PMID]

[16] Ciccotti MG, Pollack KM, Ciccotti MC, D'Angelo J, Ahmad CS, Altchek D, et al. Elbow Injuries in professional baseball epidemiological findings from the major league baseball injury surveillance system. The American Journal of Sports Medicine. 2017; 45(10):2319-28. [DOI:10.1177/0363546517706964] [PMID]

[17] Carr JB, Chicklo B, Altchek DW, Dines JS. On-field management of shoulder and elbow injuries in baseball athletes. Current Reviews in Musculoskeletal Medicine. 2019; 12(2):67-71. [DOI:10.1007/s12178-019-09535-9] [PMID] [PMCID]

[18] Pletcher E. The effects of consecutive softball windmill pitches on coordination patterns and variability, muscular strength, and pitching performance. [PhD dissertation]. Pittsburgh: University of Pittsburgh; 2017. http:/ / d-scholarship.pitt.edu/31497/

[19] Camp CL, Wang D, Sinatro AS, D'Angelo J, Coleman SH, Dines JS, et al. Getting hit by pitch in professional baseball: analysis of injury patterns, risk factors, concussions, and days missed for batters. The American Journal of Sports Medicine. 2018; 46(8):1997-2003. [DOI:10.1177/0363546518773048] [PMID]

[20] Myers JB, Lephart SM. The role of the sensorimotor system in the athletic shoulder. Journal of Athletic Training. 2000; 35(3):351-63. [PMID] [PMCID]
[21] McQuade KJ, Dawson J, Smidt GL. Scapulothoracic muscle fatigue associated with alterations in scapulohumeral rhythm kinematics during maximum resistive shoulder elevation. Journal of Orthopedic \& Sports Physical Therapy. 1998; 28(2):74-80. [DOI:10.2519/jospt.1998.28.2.74] [PMID]

[22] Rahnama N, Reilly T, Lees A. Injury risk associated with playing actions during competitive soccer. British Journal of Sports Medicine. 2002; 36(5):354-9. [DOI:10.1136/ bjsm.36.5.354] [PMID] [PMCID]

[23] Small K, McNaughton L, Greig M, Lovell R. The effects of multidirectional soccer-specific fatigue on markers of hamstring injury risk. Journal of Science and Medicine in Sport. 2010; 13(1):120-5. [DOI:10.1016/j.jsams.2008.08.005] [PMID] 
This Page Intentionally Left Blank 